\title{
Ecological impacts of fire and postfire restoration in Korea
}

\author{
Soung Ryoul Ryu $\cdot$ Futoshi Nakamura
}

Published online: 22 October 2013

(C) International Consortium of Landscape and Ecological Engineering and Springer Japan 2013

Fire is a major driving force shaping and maintaining the integrity of various forest ecosystems. In particular, pine forests often depend on fire for sustainability, because fire removes the organic layer of the forest floor to prepare a desirable seedbed and helps eliminate competitors. The majority of Korean forests are dominated by pine species, because pine forests were historically protected for various purposes (e.g., source for building material), and pine species were widely planted in the 1960s and 1970s to restore the barren soil that resulted from the Korean War and excessive natural resource extraction since 1907. Fires, however, have been excluded from the modern Korean landscape for an extended time mainly due to an aggressive fire exclusion policy and low fuel loading to sustain crown fires. Consequently, it is not clearly known how dominant native species (e.g., Pinus densifora, P. thunbergii, and Quercus mongolica) interact with fire in Korea and how fire influences interspecific competition among them. Naturally, the general public did not consider fire an integral and essential part of forest maintenance in Korea and believed it could only yield harmful results. Moreover, some people even believed that Korean forests could be maintained without fire.

For the first time in modern history, Korea experienced a wildland fire $>1,000$ ha in 1996 (3,762 ha), which was followed by several large fires, including the Eastern Coastal Fire in 2000 that burned 23,794 ha (or

\section{S. R. Ryu ( $\square)$}

Department of Renewable Resources, University of Alberta, Edmonton, AB T6G 2H1, Canada

e-mail: soung.ryu@ualberta.ca

F. Nakamura

Laboratory of Forest Ecosystem Management, Graduate School of Agriculture, Hokkaido University, Sapporo 060-8589, Japan approximately $0.4 \%$ of Korea's total forest) in 9 days. These series of fires concerned the general public for two reasons: (1) people became aware that large-scale fires $(>1,000$ ha) can occur in Korea, and (2) forest fire can threaten daily life because many people live very close to the forest (two thirds of Korea is forest). Climate change is also believed to increase wildfire intensity and size, and high fuel loading that is a result of a fire exclusion policy exacerbates it. These circumstances emphasize the need to understand fire regime and behavior in Korea. Various studies were also conducted pertaining to fire prevention and prediction and forest restoration and ecology over the last 15 years. Synthesizing and sharing current knowledge regarding fire science in Korea with the community will generate better synergism.

This special issue contains five contributions intended to describe the effects of forest fires on forest ecosystems in eastern coastal areas of Korea and provide an overview of restoration projects. The first contribution, by Ahn et al. (2013) provides a review of studies in Korea over the last two decades and compares findings with other such studies worldwide. Their review covers various fire ecology topics (i.e., postfire stand dynamics, soil property, water quality, and fire effects on insects and soil fauna), as well as postfire restoration planning issues (i.e., pine restoration, fuel breaks, and soil erosion). This work summarizes up-to-date fire science studies in Korea and help readers understand the dynamics of fires in Korea. Moreover, it helps researchers identify future study needs.

Korea has approximately $1,300 \mathrm{~mm}$ of annual precipitation, approximately half of which falls in July and August; forest fires generally occur in April and May. Generally, the forest canopy intercepts more than half of the precipitation, and removal of the forest canopy increases soil erosion owing to increased water volume and 
the physical impact of rain. Heavy rainfall after a forest fire can cause severe landslides, resulting in serious loss of life and property, particularly in adjacent residential areas. Consequently, it is critical to restore or revegetate the burned landscape quickly and prevent secondary disasters, such as landslides. The contribution of Kim et al. (2012) proves that fertilization facilitates seedling establishment and growth, which in turn improves vegetation restoration. Furthermore, Lee et al. (2013a) show how various restoration structures influence the movement of surface soil. There is no question that restoration efforts help hasten revegetation, but it is as yet unknown how these artificial processes influence other natural processes, such as bird habitat, for example. In their contribution, Choi et al. (2013) therefore attempt to quantify the impact of artificial restoration efforts on bird communities.

Burn severity usually indicates the impact of fire on ecological processes, and, therefore, it is believed that burn severity is related to postfire vegetation recovery. The relationship, however, is not yet clearly understood. Specifically, very little research has been conducted on how vegetation type and/or forest legacy interacts with burn severity to affect postfire vegetation. The study reported by Lee et al. (2013b) is a pioneering effort to evaluate such relationships.

We appreciate the valuable contributions of all authors and their rigorous efforts to improve the quality of their contributions. This issue would not have been possible without their dedication to data collection and analysis, and the many sleepless nights filled with deep thoughts. We hope this special issue provides a stepping stone for future studies on this highly valuable subject.

\section{References}

Ahn YS, Ryu SR, Lim J, Lee CH, 5, Shin JH, Choi WI, Lee B, Jeong JH, An KW, Seo JI (2013) Effects of forest fires on forest ecosystems in eastern coastal areas of Korea and an overview of restoration projects. Doi:10.1007/s11355-013-0212-0

Choi CY, Lee EJ, Nam HY, Lee WS, Lim JH (2013) Temporal changes in the breeding bird community by post-fire treatments after the Samcheok forest fire in Korea. Doi: 10.1007/s11355012-0203-6

Kim YS, Byun JK, Kim C, Park BB, Kim YK, Bae SW (2012) Growth response of Pinus densiflora seedlings to different fertilizer compound ratios in a recently burned area in the eastern coast of Korea. Doi: 10.1007/s11355-012-0208-1

Lee CW, Seo JI, Youna HJ, Kim K (2013a) Effectiveness of rehabilitation treatments on a slowly revegetating hillslope in a recently burned coastal forest, Republic of Korea. Doi: 10.1007/ s11355-013-0218-7

Lee JM, Lee SW, Lim JH, Won MS, Lee HS (2013b) Effects of heterogeneity of pre-fire forests and vegetation burn severity on short-term post fire vegetation density and regeneration in Samcheok, Korea. Doi: 10.1007/s11355-013-0214-y 